\title{
A Study on Addiction Prevention Program According to Risk Factors and Crisis Level among Adolescence
}

\author{
Nan-Sook Kim ${ }^{1}$, Mi-Na Lee ${ }^{2}$ \\ ${ }^{I}$ The Doctor's Course, Department of Human Service Education, Kwangshin University, South Korea, \\ sook4474@naver.com \\ ${ }^{2}$ Professor, Welfare Counseling Convergence Department, Kwangshin University, South Korea, \\ lmn4780@naver.com
}

Corresponding author: Mi-Na Lee

\begin{abstract}
This study is aimed to investigate on the development of addiction prevention programs according to risk factors and crisis levels in adolescence, as there are growing concerns about dysfunctional use due to the rapid distribution of smart devices. To this end, a basic study is conducted on addiction prevention programs by investigating the risk factors and crisis levels of adolescents, and deriving risk factors and problems. The survey was conducted on 1,599 teenagers located in J-gun, Jeollanam-do from September to October 2020. Based on the results, it is suggested to plan a smartphone addiction prevention program for teenagers. First, the researchers recognize the side effects of smartphone features, overuse, and the correct usage. Second, it regulates and applies the temptation and habitual use of smartphones. Third, it does not rely on smartphones and plans how to deal with stress. According to the study, crisis intervention should be made for each crisis level of adolescents. In particular, high-risk groups were high in crisis issues such as smartphone addiction, drug use, and gambling. Systematic and professional intervention is needed to prevent crisis problems depending on gender and school level. Therefore, the demand for addiction prevention programs for adolescents is needed, and self-control and impulse control should be included.
\end{abstract}

Keywords: Risk Factors, Protective Factors, Crisis Level, Addiction Prevention Program,Youth in Crisis

\section{Introduction}

As of June 2020, there were 28 local governments with a youth population of 4,000 or less, and one county with a youth population of 1,000 or less. There are 58 local governments with a school-age population between the ages 9 and 18, with less than 4,000 and three counties with less than 1,000. The priority importance of media-specific use among adolescents in 2018 is as follows. In everyday life, $82.5 \%$ of teenagers said smartphones were the most important, followed by $7.6 \%$ for television and $7.1 \%$ for other media. In their $20 \mathrm{~s}$, smartphones accounted for $81.5 \%$, followed by televisions with $11.4 \%$ and other media with $6.6 \%$. Magazines, radios, newspapers, and books, among others, said they were not important. Through these data, analog media such as type media and radio are less important to teenagers, while digital electronic media are more important.

Adolescence is the beginning of physical development into adults by having biological reproductive capacity. This physical maturity is completed around the age of 18 and adolescents are potentially or

Received: April 29, 2021; $1^{\text {st }}$ Review Result: June 12, 2021; $2^{\text {nd }}$ Review Result: July 30, 2021

Accepted: August 30, 2021 
intentionally aware of themselves as adults from this time on. But society does not recognize adolescence as an adult right after it is over. This is inconsistent with the end of puberty, which means full maturity. The onset of a biological standard of adolescence is around the age of 11-12 years. Adolescence is a time when appropriate intervention is needed because it is prone to psychological, emotional, and behavioral problems due to individual and environmental factors. If the youth problem persists in the long term, it can cause problems at the national and social levels, so a diversified approach is needed to identify and prevent these youth problems in advance.

Prevention is a priority for youth problems rather than treatment of crisis situations. Thus, active efforts should be made to identify crisis or protection factors affecting local adolescents and to reduce crisis factors and increase protection factors through this.

One out of every five smartphone users in Korea is at risk of over-dependence, which is likely to experience problems in their daily lives due to excessive immersion in smartphones. In particular, about one out of every three teenagers is at risk of over-dependence, so caution is required. According to a 2019 smartphone over-dependence survey released by the Ministry of Science and ICT with the Korea Information Society Promotion Agency, the percentage of over-dependent risk groups among Korean smartphone users increased 0.9 percent year-on-year to 20 percent. If you look at it by age, it's three years old.In the case of 9-year-old children, the risk group of over-dependence on smartphones increased $2.2 \%$ to $22.9 \%$. In particular, $30.2 \%$ of adolescents aged 10 to 19 said they were overdependent. Compared to adults, $18.8 \%$ of adults and $14.9 \%$ of older adults were found to have the highest smartphone dependence among adolescents at $30.2 \%[1]$. This is because mental health in adolescence is linked to the quality of life throughout life and is highly related to social problems. According to a World Health Organization survey, $20 \%$ of adolescents experience mental health problems every year [2][3].

The frequency of smartphone use is falling deeply into the center of our lives without our knowledge. Addiction includes categories of impulse control disorders and substance use disorders in medical terms. In other words, a condition in which it is difficult to control an impulse to a particular target along with a substance use disorder is called addiction. A study of youth smartphone addiction and depression showed that smartphone addiction directly affects suicidal thoughts and has an adverse effect on selfhabit or behavior control[4]. In other words, smartphone addiction is deepening.

Adolescents are not good at self-regulation, so overuse of smartphones causes loneliness and anxiety due to poor academic performance and poor peer relationships, and if they stay in a virtual world such as games for a long time, they experience difficulties in solving problems encountered in reality[5]. As such, smartphone addiction causes daily life disorders such as difficulty in moderation, difficulty in impulse control, and anxiety[6], and the stronger the tendency of smartphone addiction, the higher the degree of anxiety and depression[7]. Other studies have shown that aggression, depression, and selfcontrol have a high correlation between smartphone addiction and over-dependence, leading to problems in psychological areas such as depression, anxiety, aggression, atrophy, and decreased attention span [8][9]. In addition, school violence is constantly emerging in social relations related to smartphone addiction, and pornography and violent games are continuously exposed[10]. When looking at program studies to prevent smartphone addiction, there are studies related to impulse control and self-control to control personal factors of smartphone addiction. Impulsivity has shown that adolescence lacks the ability to restrain inappropriate behavior according to contextual demands in response to planning and task situations[11].

Self-control is said to be able to properly cope with the demands of the environment, initiate or stop activities according to situational needs, control the intensity and frequency of verbal and physical activities in social and educational scenes, and perform socially recognized actions without external surveillance. It is said that a person with self-control sacrifices or gives up his or her present small satisfaction and pursues the act of feeling more delayed but great satisfactory. In other words, there is a 
study that says that the higher the self-control, the lower the addiction to smartphones. There was a study about the effects of smartphone addiction on the body and mind and the factors of smartphone addiction[12]. As a result of conducting addiction prevention programs for elementary school students, self-control and self-respect were improved. Therefore, this study is intended to gather basic information on smartphone addiction prevention programs for youths in crisis.

\section{Fundamentals of Smartphone Addiction Prevention Programs}

The basic of smartphone addiction prevention programs can be summarized based on data from prior research. First, self-control, impulsivity, and aggression control are needed among studies to prevent smartphone addiction among teenagers. In addition, the need for smartphone recognition and smartphone replacement activities should be recognized as a way to understand and control the characteristics of smartphones themselves. This suggests that it is important for smartphone users to choose and act on the right way to use them by improving their self-management skills. Finally, overuse of smartphones is classified as a risk group in the smartphone addiction self-diagnosis scale test, so the contents of the program can be organized in consideration of adolescents' developmental stage, cognitive level, and interest.

The goal of smartphone addiction prevention program is as follows. First, it correctly establishes awareness of smartphones by looking at smartphone functions and pros and cons and problems caused by excessive use of smartphones, and side effects after overuse of smartphones. Second, we improve self-control by learning and applying how to resist the temptation of habitual use of smartphones and how to control smartphone use. Third, we try to maintain friendship and to plan exciting and fun activities instead of relying on smartphones in stressful situations.

The program consists of a total of 10 sessions according to the goals of the above program, and the contents of each session are as follows.

In the first session, the program is guided, and in consideration of the smartphone addiction program, an alias that comes to mind regarding the smartphone usage is first used, and other free aliases are used. In the second session, we talked about problems caused by using smartphones, and discussed indiscriminate use by sharing feelings with each other while looking at pictures of people experiencing problems in their daily lives using smartphones.

The third session is designed to identify side effects of obtaining information only from smartphones and explore and practice various ways to help save long-term memories. In the fourth session, while looking for ways to live without relying on smartphones during school and daily life, we thought of alternatives such as using diaries, schedules, and notebook notes. The fifth session explored and discussed alternative activities for using smartphones and sought ways to maintain friendship without smartphones and to facilitate communication without smartphones. In the sixth session, we thought of what we can lose from smartphone addiction, planned activities that can replace smartphone use, and shared specifically whose plans are more useful. In the seventh session, we recognized various stress and talked with friends about how to solve stress, and exchanged information with each other to find out specific measures. In the eighth session, we expressed the names of various emotions and looked at situations that are used as negative elements of smartphones. In particular, we explored and applied control measures for impulsivity and aggression while learning how to use smartphones properly. The ninth session explored the importance of precious time and made a timetable for using smartphones and developed practical methods. At the end of the last 10 sessions, we organized the contents of the session as a whole, shared what we felt, learned, and felt, and our opinions after writing a statement. After the overall program, they are expected to be able to guide their friends to practice by looking at the selfchanges made and practiced according to the contents of the program. 


\section{Research Methods}

\subsection{Subjects of the Study}

In this study, the Youth Counseling and Welfare Center in Jeonranam-do identified the degree of crisis among youths through a survey. A total of 1,599 adolescents were eligible, with 815 male students (51\%) and 784 female students (49\%).

\subsection{Research Tools}

This study used the youth crisis survey developed by the Korea Youth Counseling and Welfare Development Institute (2016)[13] and focused on risk and protection factors.

The questionnaire was used based on the results of investigating the crisis situation of adolescents using the survey questions developed by the Korea Youth Counseling and Welfare Development Institute (2016). The questions consisted of risk factors (38 questions), protective factors (15 questions), crisis outcomes (44 questions), and basic demographic questions.

\subsubsection{Risk Factors}

Sub-factors for measuring risk factors are individual, family, school, community and peer areas. Individual areas were classified as depression, anxiety, aggression, impulsivity and carelessness (16 questions), family areas were classified as parent conflicts, neglect, dysfunctional family members (11 questions), school areas as community harmful environments (3 questions) and peer areas as flight friends ( 4 questions). The total number of questions is 38 . The test tool's response method used a fivepoint Likert scale ranging from "not at all ( 0 point)" to "very much so (4 points). The reliability coefficient (Cronbach's $\alpha$ ) in this study is $\alpha=.91$, hypothesis (1) $\alpha=.83$, school $\alpha=.70$, hypothesis (2) $\alpha=.68$, community $\alpha=.81$, and peer $\alpha=.72$, which is the overall risk factor $\alpha=.72$.It turned out to be 85 . The risk factor statement composition is the same as [Table 1].

[Table 1] Configuring Risk Factor Statements

\begin{tabular}{c|c|c|c|c}
\hline \multicolumn{2}{c|}{ Sortation } & Content & Question & Cronbach's $\alpha$ \\
\hline \multirow{5}{*}{ Risk } & Individual & Depression, anxiety, aggression, impulsivity, carelessness & 16 & .91 \\
\cline { 2 - 5 } & Family & Conflicts between parents, conflicts with parents, neglect & 8 & .83 \\
\cline { 2 - 5 } & School & Inadaptation to school life & 4 & .70 \\
\cline { 2 - 5 } & Community & Harmful environment for local communities & 3 & .81 \\
\cline { 2 - 5 } & Family2 & Problem family member & 3 & .68 \\
\cline { 2 - 5 } & Peer group & Juveniles delinquency & 4 & .72 \\
\cline { 2 - 5 } & Total & & 38 & .85 \\
\hline
\end{tabular}

\subsubsection{Protective Factors Sub-regions for Measuring Protective Factors are Individual, Family, School, Community and Peer Areas.}

Individual areas were classified as self-respect, sense of purpose, and active response (5 questions). Family areas were classified as family interests and trust (3 questions), peer areas as friendships (2 questions), school areas as teachers' interests and relationships (2 questions), and community areas as support systems ( 3 questions). The total number of questions is 15 questions, and the test tool uses a five-point Likert scale that evaluates from "not at all (0 point)" to "very yes (4 points)." The reliability 
factor (Cronbach's $\alpha$ ) in this study is $\alpha=.76$ for individuals of protection factors, $\alpha=.84$, peer $\alpha=.78$, school $\alpha=.80$ and community $\alpha=.77$ for total protection factors.It turned out to be 86 . The protection factor statement composition is the same as [Table 2].

[Table 2] Construct Protection Factor Statements

\begin{tabular}{c|c|c|c|c}
\hline \multicolumn{2}{c|}{ Sortation } & Contents & Questions & Cronbach's $\alpha$ \\
\hline \multirow{4}{*}{$\begin{array}{c}\text { Protection } \\
\text { Factor }\end{array}$} & Individual & Self-respect, awareness of goals, and active response & 5 & .76 \\
\cline { 2 - 5 } & Family & Family interest and trust & 3 & .84 \\
\cline { 2 - 5 } & Peer group & Friendship & 2 & .78 \\
\cline { 2 - 5 } & School & Teachers' Interests and Relationships & 2 & .80 \\
\cline { 2 - 5 } & Community & Support & 3 & .77 \\
\cline { 2 - 5 } & Total & & 15 & .86 \\
\hline
\end{tabular}

\subsection{Data Analysis}

The Youth Crisis Survey of this study reused the contents of the survey results conducted at the J Youth Counseling and Welfare Center. Frequency analysis was conducted and used to identify the general characteristics of J-group adolescents. As a result of the implementation, the protection factors, risk factors, and counseling awareness were identified, and the reliability of each factor was calculated. Also, a group-by-group average analysis according to the general characteristics of gender and school type was conducted.

\section{Research Results}

\subsection{Characteristics of the Person Surveyed}

The characteristics of the person surveyed are as shown in [Table 3].

[Table 3] Characteristics of Investigated Subjects

\begin{tabular}{c|c|c|c}
\hline \multirow{2}{*}{ Gender } & Male & Number of subjets & Rate(\%) \\
\cline { 2 - 4 } & Female & 815 & 41 \\
\hline \multirow{3}{*}{ Types of Juvenile } & Dlementary school students & 784 & 27 \\
\cline { 2 - 4 } & Middle school students & 432 & 43.6 \\
\cline { 2 - 4 } & High school students & 470 & 29.4 \\
\hline
\end{tabular}

According to the characteristics of the survey subjects as shown in Table 4-1, there are 1,599 students, 815 boys (51\%), 784 girls (49\%); 432 elementary school students (27\%), 697 middle school students $(43,6 \%)$, and 470 high school students $(29.4 \%)$.

\subsection{Analysis of Crisis Outcomes by Gender}

The results of analysis of crisis results by gender are as follows [Table 4]. 
[Table 4] Crisis Results by Gender and Area

\begin{tabular}{|c|c|c|c|c|c|}
\hline & \multirow{2}{*}{ Question } & \multirow{2}{*}{ Sortation } & \multicolumn{2}{|c|}{$\exp ($ rate; $\%)$} & \multirow{2}{*}{$\chi^{2}$} \\
\hline & & & Have not & Have & \\
\hline \multirow{15}{*}{$\begin{array}{l}\text { Addition of } \\
\text { smartphone and } \\
\text { internet }\end{array}$} & \multirow{3}{*}{$\begin{array}{c}\text { Over the past month, I have caused serious } \\
\text { conflicts with others (parents, teachers, etc.) due } \\
\text { to the use of the Internet or smartphones (game, } \\
\text { chat, etc.). }\end{array}$} & $\mathrm{M}$ & $603(74.0)$ & $212(26.0)$ & \multirow{3}{*}{0.411} \\
\hline & & $\mathrm{F}$ & $591(75.4)$ & $193(24.6)$ & \\
\hline & & Total & $1194(74.7)$ & $405(25.3)$ & \\
\hline & \multirow{3}{*}{$\begin{array}{l}\text { I haven't been able to do what I've planned in the } \\
\text { past month due to the use of the Internet or } \\
\text { smartphones (game, chat, etc.). }\end{array}$} & $\mathrm{M}$ & $507(62.2)$ & $308(37.8)$ & \multirow{3}{*}{$45.402 * *$} \\
\hline & & $\mathrm{F}$ & $356(45.4)$ & $428(54.6)$ & \\
\hline & & Total & $863(54.0)$ & $736(46.0)$ & \\
\hline & \multirow{3}{*}{$\begin{array}{l}\text { I've been playing games or chatting for more } \\
\text { than three to four hours a day over the past } \\
\text { month. }\end{array}$} & $\mathrm{M}$ & $210(25.8)$ & $605(74.2)$ & \multirow{3}{*}{$2.595^{*}$} \\
\hline & & $\mathrm{F}$ & $175(22.3)$ & $609(77.7)$ & \\
\hline & & Total & $385(24.1)$ & $1214(75.9)$ & \\
\hline & \multirow{3}{*}{$\begin{array}{l}\text { There have been times in the past month when I } \\
\text { haven't been able to live my daily life because } \\
\text { I've been playing games or chatting (internet, } \\
\text { smartphone), such as absenteeism, tardiness, } \\
\text { irregular eating and sleeping. There are times } \\
\text { when I can't live my daily life because I'm } \\
\text { chatting (on the Internet, on my smartphone), } \\
\text { such as absenteeism, tardiness, irregular eating } \\
\text { and sleeping. }\end{array}$} & $\mathrm{M}$ & $639(78.4)$ & $176(21.6)$ & \multirow[b]{3}{*}{$6.161 * *$} \\
\hline & & $\mathrm{F}$ & $573(73.1)$ & 211(26.9) & \\
\hline & & Total & $1212(75.8)$ & $387(24.2)$ & \\
\hline & \multirow{3}{*}{$\begin{array}{l}\text { I get restless and nervous when I can't use the } \\
\text { Internet or my smartphone. }\end{array}$} & $\mathrm{M}$ & $762(93.5)$ & $53(6.5)$ & \multirow{3}{*}{$4.341^{*}$} \\
\hline & & $\mathrm{F}$ & $711(90.7)$ & $73(9.3)$ & \\
\hline & & Total & $1473(92.1)$ & $126(7.9)$ & \\
\hline \multirow{9}{*}{ Alcoholgambling } & \multirow{3}{*}{ Having drinking for the past month. } & $\mathrm{M}$ & $772(94.7)$ & $43(5.3)$ & \multirow{3}{*}{0.034} \\
\hline & & $\mathrm{F}$ & $741(94.5)$ & $43(5.5)$ & \\
\hline & & Total & 1513(94.6) & $86(5.4)$ & \\
\hline & \multirow{3}{*}{ Having for the past month. } & $\mathrm{M}$ & $794(97.4)$ & $21(2.6)$ & \multirow{3}{*}{$0.799 *$} \\
\hline & & $\mathrm{F}$ & $769(98.1)$ & $15(1.9)$ & \\
\hline & & Total & $1563(97.7)$ & $36(2.3)$ & \\
\hline & \multirow{3}{*}{$\begin{array}{l}\text { Having using glue, butane gas, drugs, etc. for the } \\
\text { past month. }\end{array}$} & $\mathrm{M}$ & $810(99.4)$ & $5(0.6)$ & \multirow{3}{*}{0.076} \\
\hline & & $\mathrm{F}$ & $780(99.5)$ & $4(0.5)$ & \\
\hline & & Total & $1590(99.4)$ & $9(0.6)$ & \\
\hline \multirow{19}{*}{ Gambling } & \multirow{3}{*}{$\begin{array}{l}\text { Having playing online games (poker, horse } \\
\text { racing, etc) for a month. }\end{array}$} & $\mathrm{M}$ & $807(99.0)$ & $8(1.0)$ & \\
\hline & & $\mathrm{F}$ & $782(99.7)$ & $2(0.3)$ & $3.394 *$ \\
\hline & & Total & $1589(99.4)$ & $10(0.6)$ & \\
\hline & & $\mathrm{M}$ & 792(97.2) & $23(2.8)$ & \\
\hline & A game using cards & $\mathrm{F}$ & $778(99.2)$ & $6(0.8)$ & $9.493 * *$ \\
\hline & & Total & $1570(98.2)$ & $29(1.8)$ & \\
\hline & & $\mathrm{M}$ & $706(86.6)$ & $109(13.4)$ & \\
\hline & Picking games (pick dolls, pick prizes) & $\mathrm{F}$ & $705(89.9)$ & $79(10.1)$ & $4.189 * *$ \\
\hline & & Total & $1411(88.2)$ & $188(11.8)$ & \\
\hline & & $\mathrm{M}$ & $797(97.8)$ & $18(2.2)$ & \\
\hline & Bet on a sporting event & $\mathrm{F}$ & $776(99.0)$ & $8(1.0)$ & $3.527^{* *}$ \\
\hline & & Total & 1573(98.4) & $26(1.6)$ & \\
\hline & Purchase Lottery/Sports Promotion Voting & $\mathrm{M}$ & $807(99.0)$ & $8(1.0)$ & \\
\hline & Ticket & $\mathrm{F}$ & $780(99.5)$ & $4(0.5)$ & $1.192 *$ \\
\hline & (Lotto, Pension Lottery, Toto, Proto) & Total & $1587(99.2)$ & $12(0.8)$ & \\
\hline & & $\mathrm{M}$ & 792(97.2) & $23(2.8)$ & \\
\hline & $\begin{array}{l}\text { Other betting games } \\
\text { (GIFs, Ladder Riding, Bingo) }\end{array}$ & $\mathrm{F}$ & $758(96.7)$ & $26(3.3)$ & 0.329 \\
\hline & & Total & $1550(96.9)$ & $49(3.1)$ & \\
\hline & Card games in one game, Netmarble, etc. & $\mathrm{M}$ & $800(98.2)$ & $15(1.8)$ & $3.564 * *$ \\
\hline
\end{tabular}




\begin{tabular}{|c|c|c|c|c|}
\hline \multirow[t]{2}{*}{ Other betting games for online use. } & $\mathrm{F}$ & $778(99.2)$ & $6(0.8)$ & \\
\hline & Total & $1578(98.7)$ & $21(1.3)$ & \\
\hline \multirow{3}{*}{ (Online ladder, leg leg, bingo, snail, graph game) } & M & $801(98.3)$ & $14(1.7)$ & \multirow{3}{*}{0.086} \\
\hline & $\mathrm{F}$ & $769(98.1)$ & $15(1.9)$ & \\
\hline & Total & $1570(98.2)$ & $29(1.8)$ & \\
\hline \multirow{3}{*}{ Internet sports betting(TOTO, PROTO) } & $\mathrm{M}$ & $809(99.3)$ & $6(0.7)$ & \multirow{3}{*}{0.892} \\
\hline & $\mathrm{F}$ & 781(99.6) & $3(0.4)$ & \\
\hline & Total & $1590(99.4)$ & $9(0.6)$ & \\
\hline \multirow{3}{*}{$\begin{array}{l}\text { Internet casino games } \\
\text { (Black Jack, Bakara) }\end{array}$} & $\mathrm{M}$ & $810(99.4)$ & $5(0.6)$ & \multirow{3}{*}{$4.825^{* *}$} \\
\hline & $\mathrm{F}$ & $784(100.0)$ & $0(0.0)$ & \\
\hline & Total & $1594(99.7)$ & $5(0.3)$ & \\
\hline
\end{tabular}

As in [Table 4], women had a relatively higher experience rate than men in all questions except for the question of "I have caused severe conflicts with others (parents, teachers, etc.) due to the use of the Internet or smartphones (game, chat, etc.) over the past month."In the alcohol, tobacco, and drug sectors, men had a relatively higher experience rate than women in "I have smoked in the past month," and showed a statistically significant difference in the level of significance of 5\%.In the gambling area, male experience rates were higher than female in all categories except "other betting games (gIFs, ladders, bingo)," "other betting games for online" and "Internet sports betting (toto, proto), and showed statistically significant differences in significance level of 5\%.In the field of school violence (damage), men had a relatively higher experience rate than women in "I've been assaulted by friends over the past year," "I've been verbally abused by friends," and "I've been forcibly robbed of money or goods by friends or seniors over the past year," and showed statistical significance at $5 \%$.

\subsection{Types by School Grade}

Analysis of crisis results by area by type of school level is as follows [Table 5].

[Table 5] Crisis Results by School Level (Continued Table)

\begin{tabular}{|c|c|c|c|c|c|}
\hline \multirow{2}{*}{ Sector } & \multirow{2}{*}{ Questions } & \multirow{2}{*}{ Sortaion } & \multicolumn{2}{|c|}{ Exp(rate;\%) } & \multirow{2}{*}{$\mathrm{X} 2$} \\
\hline & & & Have not & Have & \\
\hline \multirow{18}{*}{$\begin{array}{l}\text { Addiction of } \\
\text { smart phone and } \\
\text { internet }\end{array}$} & \multirow{4}{*}{$\begin{array}{l}\text { Over the past month, I have been in a serious } \\
\text { conflict with others (parents, teachers, etc.) } \\
\text { because of the use of the Internet or } \\
\text { smartphones (game, chat, etc.). }\end{array}$} & Elementary & $346(80.1)$ & $86(19.9)$ & \multirow{4}{*}{$43.178^{* * *}$} \\
\hline & & Middle & $464(66.6)$ & $233(33.4)$ & \\
\hline & & High & $384(81.7)$ & $86(18.3)$ & \\
\hline & & Total & $1194(74.7)$ & $405(25.3)$ & \\
\hline & \multirow{4}{*}{$\begin{array}{l}\text { In the past month, I haven't been able to do } \\
\text { what I've planned because of the use of the } \\
\text { Internet or smartphones (game, chat, etc.). }\end{array}$} & Elementary & $273(63.2)$ & $159(36.8)$ & \multirow{4}{*}{$26.825 * * *$} \\
\hline & & Middle & $331(47.5)$ & $366(52.5)$ & \\
\hline & & High & $259(55.1)$ & $211(44.9)$ & \\
\hline & & Total & $863(54.0)$ & $736(46.0)$ & \\
\hline & \multirow{4}{*}{$\begin{array}{l}\text { Over the past month, I've played games and } \\
\text { chat (Internet and Smartphone) for more than } \\
\text { three to four hours a day. }\end{array}$} & Elementary & $147(34.0)$ & $285(66.0)$ & \multirow{4}{*}{$49.770 * * *$} \\
\hline & & Middle & $112(16.1)$ & $585(83.9)$ & \\
\hline & & High & $126(26.8)$ & $344(73.2)$ & \\
\hline & & Total & $385(24.1)$ & $1214(75.9)$ & \\
\hline & \multirow{4}{*}{$\begin{array}{l}\text { There have been times in the past month when } \\
\text { I haven't been able to live my daily life because } \\
\text { I've been playing games or chatting (internet, } \\
\text { smartphone), such as absenteeism, tardiness, } \\
\text { irregular eating and sleeping. }\end{array}$} & Elementary & $363(84.0)$ & $69(16.0)$ & \multirow{4}{*}{$22.040 * * *$} \\
\hline & & Middle & $504(72.3)$ & $193(27.7)$ & \\
\hline & & High & $345(73.4)$ & $125(26.6)$ & \\
\hline & & Total & $1212(75.8)$ & $387(24.2)$ & \\
\hline & \multirow{2}{*}{$\begin{array}{l}\text { I get restless and nervous when I can't use the } \\
\text { Internet or my smartphone. }\end{array}$} & Elementary & $396(91.7)$ & $36(8.3)$ & \multirow{2}{*}{$1.519^{*}$} \\
\hline & & Middle & $638(91.5)$ & $59(8.5)$ & \\
\hline
\end{tabular}




\begin{tabular}{|c|c|c|c|c|c|}
\hline & & High & 439(93.4) & $31(6.6)$ & \\
\hline & & Total & $1473(92.1)$ & $126(7.9)$ & \\
\hline \multirow{12}{*}{$\begin{array}{l}\text { Alcohol } \\
\text { drug }\end{array}$} & \multirow{4}{*}{ Have drinking for the past month. } & Elementary & $422(97.7)$ & $10(2.3)$ & \multirow{4}{*}{$37.239^{* * *}$} \\
\hline & & Middle & $671(96.3)$ & $26(3.7)$ & \\
\hline & & High & $420(89.4)$ & $50(10.6)$ & \\
\hline & & Total & 1513(94.6) & $86(5.4)$ & \\
\hline & \multirow{4}{*}{ Have smoking for the past month. } & Elementary & $428(99.1)$ & $4(0.9)$ & \multirow{4}{*}{$41.694 * * *$} \\
\hline & & Middle & 693(99.4) & $4(0.6)$ & \\
\hline & & High & $442(94.0)$ & $28(6.0)$ & \\
\hline & & Total & 1563(97.7) & $36(2.3)$ & \\
\hline & \multirow{4}{*}{$\begin{array}{l}\text { Have using glue, butane gas, drugs, etc. for the } \\
\text { past month. }\end{array}$} & Elementary & $428(99.1)$ & $4(0.9)$ & \multirow{4}{*}{$2.048^{*}$} \\
\hline & & Middle & 693(99.4) & $4(0.6)$ & \\
\hline & & High & $469(99.8)$ & $1(0.2)$ & \\
\hline & & Total & $1590(99.4)$ & $9(0.6)$ & \\
\hline \multirow{37}{*}{ Gambling } & \multirow{4}{*}{$\begin{array}{l}\text { Have playing online games ( poker, horse } \\
\text { racing, etc) for the last month. } \\
\text { A game using cards. }\end{array}$} & Elementary & $427(98.8)$ & $5(1.2)$ & \multirow{4}{*}{$4.957^{* *}$} \\
\hline & & Middle & $696(99.9)$ & $1(0.1)$ & \\
\hline & & High & $466(99.1)$ & $4(0.9)$ & \\
\hline & & Total & $1589(99.4)$ & $10(0.6)$ & \\
\hline & \multirow{4}{*}{ Picking games (pick dolls, pick prizes) } & Elementary & $426(98.6)$ & $6(1.4)$ & \multirow{4}{*}{$2.730^{*}$} \\
\hline & & Middle & $680(97.6)$ & $17(2.4)$ & \\
\hline & & High & $464(98.7)$ & $6(1.3)$ & \\
\hline & & Total & $1570(98.2)$ & $29(1.8)$ & \\
\hline & \multirow{4}{*}{ A bet on a sporting event } & Elementary & $345(79.9)$ & $87(20.1)$ & \multirow{4}{*}{$44.761 * * *$} \\
\hline & & Middle & $625(89.7)$ & $72(10.3)$ & \\
\hline & & High & $441(93.8)$ & $29(6.2)$ & \\
\hline & & Total & $1411(88.2)$ & $188(11.8)$ & \\
\hline & \multirow{4}{*}{ A bet on a sporting event } & Elementary & $421(97.5)$ & $11(2.5)$ & \multirow{4}{*}{$6.771^{* *}$} \\
\hline & & Middle & 684(98.1) & 13(1.9) & \\
\hline & & High & $468(99.6)$ & $2(0.4)$ & \\
\hline & & Total & 1573(98.4) & $26(1.6)$ & \\
\hline & \multirow{4}{*}{$\begin{array}{c}\text { Purchase Lottery/Sports Promotion Voting } \\
\text { Ticket } \\
\text { (Lotto, Pension Lottery, Toto, Proto) }\end{array}$} & Elementary & $424(98.1)$ & $8(1.9)$ & \multirow{4}{*}{$10.881^{* * *}$} \\
\hline & & Middle & 693(99.4) & $4(0.6)$ & \\
\hline & & High & $470(100.0)$ & $0(0.0)$ & \\
\hline & & Total & $1587(99.2)$ & $12(0.8)$ & \\
\hline & \multirow{4}{*}{$\begin{array}{l}\text { Other betting games } \\
\text { ( Ladder Riding, Bingo) }\end{array}$} & Elementary & $403(93.3)$ & $29(6.7)$ & \multirow{4}{*}{$27.032^{* * *}$} \\
\hline & & Middle & $683(98.0)$ & $14(2.0)$ & \\
\hline & & High & $464(98.7)$ & $6(1.3)$ & \\
\hline & & Total & $1550(96.9)$ & $49(3.1)$ & \\
\hline & \multirow{4}{*}{ Card/ games in one game, Netmarble, etc. } & Elementary & $422(97.7)$ & $10(2.3)$ & \\
\hline & & Middle & $688(98.7)$ & $9(1.3)$ & $6204 * *$ \\
\hline & & High & $468(99.6)$ & $2(0.4)$ & $0.204 \cdots$ \\
\hline & & Total & 1578(98.7) & $21(1.3)$ & \\
\hline & & Elementary & $415(96.1)$ & $17(3.9)$ & \\
\hline & (Online ladder, leg leg, bingo, snail, graph & Middle & $688(98.7)$ & $9(1.3)$ & $15633 * * *$ \\
\hline & game, etc.) & High & $467(99.4)$ & $3(0.6)$ & 15.033 \\
\hline & & Total & $1570(98.2)$ & $29(1.8)$ & \\
\hline & & Elementary & $426(98.6)$ & $6(1.4)$ & \\
\hline & Internet sports betting & Middle & $695(99.7)$ & $2(0.3)$ & \\
\hline & (TOTO, PROTO) & High & $469(99.8)$ & $1(0.2)$ & $7.244^{2 N}$ \\
\hline & & Total & $1590(99.4)$ & $9(0.6)$ & \\
\hline & Internet casino games & Elementary & $428(99.1)$ & $4(0.9)$ & $7.326^{* *}$ \\
\hline
\end{tabular}


(Black Jack, Bakara)

\begin{tabular}{ccc} 
Middle & $696(99.9)$ & $1(0.1)$ \\
\hline High & $470(100.0)$ & $0(0.0)$ \\
\hline Total & $1594(99.7)$ & $5(0.3)$
\end{tabular}

As in [Table 5], middle schools showed the highest experience rate in all questions in the area of Internet and smartphone addiction, and showed statistically significant differences in significance level of 5\%.In the alcohol, tobacco, and drug sectors, high schools showed the highest experience rate in "I have drunk in the past month" and "I have smoked in the past month," and showed statistically significant differences in the significance level of 5\%.In the gambling domain, all questions showed statistically significant differences at a significant level of 5\%. Elementary schools showed a relatively high experience rate in all questions except for the question "I have been forcibly deprived of money or goods by my friends or seniors over the past year," and showed a statistically significant difference in all questions at a significant level of $5 \%$.

\subsection{Conflict with Others Due to Smartphones}

The results of the measurement by the characteristics of the smartphone addiction crisis results, "I have caused severe conflicts with others (parents, teachers, etc.) due to the use of smartphones (game, chat, etc.) over the past month," are as follows [Table 6].

[Table 6] Conflicts with Others Due to Smart Phones

\begin{tabular}{|c|c|c|c|c|c|c|}
\hline \multicolumn{2}{|r|}{ Sortation } & Never & Once & 2 or 3 times & $\begin{array}{c}\text { Once and twice a } \\
\text { week }\end{array}$ & Everyday \\
\hline \multicolumn{2}{|r|}{ All } & $1194(74.7)$ & $227(14.2)$ & $116(7.3)$ & $43(2.7)$ & $19(1.2)$ \\
\hline \multirow{2}{*}{ Gender } & M & $603(74.0)$ & $121(14.8)$ & $64(7.9)$ & $19(2.3)$ & $8(1.0)$ \\
\hline & $\mathrm{F}$ & $591(75.4)$ & $106(13.5)$ & $52(6.6)$ & $24(3.1)$ & $11(1.4)$ \\
\hline \multirow{3}{*}{$\begin{array}{l}\text { Types of } \\
\text { juvenile }\end{array}$} & Elementary students & $346(80.1)$ & $43(2.7)$ & $28(6.5)$ & $11(2.5)$ & $4(0.9)$ \\
\hline & Middle school students & $464(66.6)$ & $126(18.1)$ & $68(9.8)$ & $27(3.9)$ & $12(1.7)$ \\
\hline & High school students & $384(81.7)$ & $58(12.3)$ & $20(4.3)$ & $5(1.1)$ & $3(0.6)$ \\
\hline
\end{tabular}

If you look at the overall response rate as shown in [Table 6], 1,194 (74.7\%) responded never, 227 (14.2\% of No. 1) answered once, 116 (7.3\% of No. 2-3) answered 2 or 3 times, 43 (2.7\% of No. 1-2 weekly) answered once or twice a week, and 19 (1.2\% of No. 1 daily) answered everyday.

\subsection{Correlation Between Risk Factors and Crisis Outcomes}

The results of the correlation between risk factors and crisis outcomes are shown in [Table 7].

[Table 7] Correlation Between Risk Factors and Crisis Outcomes

\begin{tabular}{|c|c|c|c|c|c|c|c|c|}
\hline Risk factors & $\begin{array}{l}\text { Depression } \\
\text { and } \\
\text { anxiety }\end{array}$ & $\begin{array}{l}\text { Aggression, } \\
\text { impulsiveness, } \\
\text { carelessness }\end{array}$ & $\begin{array}{l}\text { Conflicts with } \\
\text { parents and } \\
\text { neglect }\end{array}$ & $\begin{array}{l}\text { Parental } \\
\text { conflict }\end{array}$ & $\begin{array}{l}\text { Problematic } \\
\text { Family } \\
\text { Member }\end{array}$ & $\begin{array}{c}\text { School } \\
\text { lifemaladaptation }\end{array}$ & $\begin{array}{c}\text { Harmful } \\
\text { environment } \\
\mathrm{n} \quad \text { for local } \\
\text { communities }\end{array}$ & $\begin{array}{l}\text { Violation of } \\
\text { the rules }\end{array}$ \\
\hline $\begin{array}{c}\text { Internet and smart } \\
\text { phone addiction }\end{array}$ & $.301 * *$ & $.339 * *$ & $.196 * *$ & $.163 * *$ & $.114^{* *}$ & $.263 * *$ & $.193^{* *}$ & $.147 * *$ \\
\hline $\begin{array}{c}\text { Alcohol, cigarettes, } \\
\text { drugs }\end{array}$ & $.114^{* *}$ & $.147 * *$ & $.203 * *$ & $.109 * *$ & $.098 * *$ & $.083 * *$ & $.162 * *$ & $.378 * *$ \\
\hline Gambling & $.056^{* *}$ & $.131 * *$ & $.053 *$ & $.102 * *$ & $.112 * *$ & .035 & $.130 * *$ & $.090 * *$ \\
\hline
\end{tabular}


As shown in [Table 7], the correlation between crisis results and risk factors shows a statistically significant positive correlation at most significance levels of 5\%, which is mostly weak (more than .03 ). Those less than three showed aa correlation. In terms of factors that are more correlated than other factors, aggression, impulsivity, carelessness $(\mathrm{r}=.339)$ and depression and anxiety $(\mathrm{r}=.301)$ were found in Internet and smartphone addiction, and conflict and neglect with parents $(\mathrm{r}=.378)$ in alcohol, tobacco, and drugs.It was shown as 203 , and in gambling, aggression, impulsivity, carelessness $(\mathrm{r}=.131)$ and harmful environment to the community $(\mathrm{r}=.130)$. Overall, the risk factors that have the biggest relationship to the crisis results were aggression, impulsivity, carelessness, depression and anxiety, conflict with delinquent friends, parents, and environmental factors harmful to the community.

\subsection{Correlation Between Protective Factors and Crisis Outcomes}

The correlation between protective factors and crisis outcomes is shown in [Table 8].

[Table 8] Correlation Between Protective Factors and Crisis Outcomes

\begin{tabular}{c|clccc}
\hline Risk factors & Individual & Family & Peer group & School & Community \\
\hline Crisis result & & & & & \\
\hline Internet and smart phone addiction & $-.197^{* *}$ & $-.141^{* *}$ & $-.104^{* *}$ & $-.151^{* *}$ & $-.218^{* *}$ \\
\hline Alcohol, cigarettes, drugs & $-.055^{*}$ & $-.072^{* *}$ & -.027 & $-.029^{* *}$ & $-.218^{* *}$ \\
\hline Gambling & -.029 & $-.055^{*}$ & -.001 & $-.075^{* *}$ & -.038 \\
\hline${ }^{*} \mathrm{p}<.05,{ }^{* *} \mathrm{p}<.01$ & & & &
\end{tabular}

As shown in [Table 8], the correlation between overall crisis outcomes and risk factors was statistically significant at a significance level of $5 \%$, mostly weak (.001 or higher $\sim$ ). Those less than two showed a negative correlation. The results of the crisis, which are relatively high negatively correlated with each gastric attachment factor, show that in Internet and smartphone addiction, the community $(\mathrm{r}=-.218)$, and the individual ( $\mathrm{r}=-.197)$ was shown to be a factor. Alcohol, tobacco, and drugs showed community $(\mathrm{r}=-.218)$, household $(\mathrm{r}=-.072)$, and gambling showed school $(\mathrm{r}=-.075)$, and household $(\mathrm{r}=-.055)$. Overall, the risk factors that have the greatest relationship to the outcome of the crisis were the communities, individuals, families, and schools.

\section{Discussion and Suggestion}

\subsection{Discussion}

Juvenile counseling aimed to identify the degree of crisis among local youths, determine the direction of future operation, and conduct a fact-finding survey to develop and support effective counseling education support programs. The 2020 Crisis Survey used the 2016 Youth Crisis Measure developed by the Korea Youth Counseling and Welfare Development Institute. It is intended to provide basic data for responding sensitively to changes in youth issues and preparing various community-oriented support measures that include parents, families, schools, etc.

The results of this study are as follows.

First, we categorize crisis levels into four groups: high-risk groups, risk groups, potential risk groups, and general groups. The frequency and rate of each crisis level group were calculated. As a result, it was classified as $0.4 \%$ in the high-risk group, $1.5 \%$ in the risk group, $15.5 \%$ in the potential risk group, and $82.6 \%$ in the general group. In addition, $17.4 \%$ of all adolescents were at risk levels that should be supported with policy interest. Therefore, it is necessary to implement and support programs to prevent 
the occurrence of crisis youths in advance, given that the proportion of potential risk groups and onesided teenagers is higher than the proportion of high-risk groups and risk groups.

Second, among the gender-specific crisis results, female teenagers were higher than male teenagers, while male teenagers were higher than female teenagers. From this point of view, female teenagers are more exposed to Internet and smartphone addiction problems due to SNS use and chatting, while male teenagers are more exposed to direct use of drugs such as alcohol, cigarettes, and bonds. In addition, in the case of online gambling problems, male teenagers were slightly higher than female teenagers. In the case of school violence, male teenagers were higher than female teenagers while male teenagers were also higher than female teenagers. This can be seen as reflecting the tendency of male teenagers to externalize their behavior. According to many documents related to flight, it is consistently reported that external flight problems such as violence are common in male teenagers. On the other hand, internalization problems such as depression and anxiety have been reported in female teenagers. This characteristic is also shown in this study. In the case of suicide, female teenagers were higher than male teenagers. This reflects the fact that female teenagers may be somewhat vulnerable in dealing with stress in emotional areas such as depression and anxiety and crisis situations. Therefore, male teenagers need to develop and support programs to prevent behavioral problems such as drug problems, online gambling problems, and school violence problems, and female teenagers need to develop and support programs to prevent emotional problems with depression, anxiety and suicide.

Third, the results of the crisis by school level showed that Internet and smartphone addiction problems were higher in the order of middle school, high school, and elementary school, suggesting the need to strengthen counseling and treatment programs for middle and high schools. According to the 2016 Internet Overdependence Survey conducted by the Ministry of Science, ICT and Future Planning and the Korea Information Society Agency, teenagers were the highest among all age groups with $30.6 \%$ of the total over-dependent risk group. Therefore, it is necessary to come up with intervention measures for all teenagers in the jurisdiction as well as Internet, smartphone, and prevention and resolution programs for teenagers in fourth grade elementary school and first grade middle and high school. In the case of drug problems, high schools showed a higher proportion of drug problems than other school levels. Gambling problems were found to be higher in elementary schools than in other schools in flight problems. This requires specialised counseling and program development to prevent drug and flight problems for high school students. In the case of school violence damage and assault, elementary schools and middle schools were found to be more severe than other school levels. In the case of suicide, elementary schools showed more serious problems than other schools, and abuse and neglect problems were also higher in elementary schools. This suggests the need for specialized professional counseling programs on psychological and emotional difficulties and stress response to prevent suicide of elementary school students. In addition, middle schools showed a higher $\%$ of sex problems by school except elementary school and all school levels were less than $1.0 \%$, of which elementary schools were higher.

Park Jung-ah[14] said that the higher the tendency to seek immediate satisfaction, the higher the tendency to become addicted to smartphones, and that developing behavioral inhibition and emotional inhibition can be a major factor in preventing problematic behavior caused by anger and aggression. In other words, high self-control increases resistance to impulsivity and temptation, which helps to refrain from using indiscriminate smartphones and to use planned smartphones. It supports the results of a prior study[15], which reported that there is an inadequate correlation between smartphone addiction and selfcontrol, as the actual participating group member said in a speech that smartphone usage time has decreased due to the ability to control smartphones. Therefore, smartphone addiction prevention programs have a positive effect on reducing smartphone addiction by improving children's self-control. 


\subsection{Suggestion}

Based on the results of a fact-finding survey on juvenile crises and discussions, the following policy suggestions shall be made:

First, it is necessary to cooperate with regional links and establish an efficient linkage system between related agencies.

As shown in the survey results of youth conditions, the problems faced by teenagers are diverse and complex. Youth-related issues are related to several places, including the Ministry of Gender Equality and Family, the Ministry of Education, the Ministry of Health and Welfare, the Ministry of Justice, the Ministry of Science, ICT and the National Police Agency. This is because such diverse and complex problems are difficult with the efforts of any single organization. Therefore, it is essential to establish an integrated service support system for regional-linked cooperative organizations or related organizations. Second, customized crisis intervention by crisis level for teenagers should be made. Highrisk groups showed a high percentage of crisis problems such as Internet and smartphone addiction, drug use, school violence damage, and suicide problems. This suggests that active and enhanced prevention education and intervention measures for high-risk groups are needed. As a result, customized programs based on the types of crisis problems and crisis levels for teenagers revealed through the youth crisis survey should be developed and professional intervention should be made. It is also necessary to expand the number of professionals who can run the developed program professionally. Third, systematic and professional interventions should be made to prevent and resolve crisis problems by gender and school level.

According to the results of the survey, female teenagers had a higher percentage of Internet and smartphone addiction and suicide problems than male teenagers, while male teenagers had a higher $\%$ of online gambling and school violence problems. In the case of crisis results by school level, many problems, such as drug problems, gambling, and flight problems, showed a higher proportion of high schools, while middle schools showed a higher proportion of middle schools than other school levels. Therefore, it is important to systematically conduct preventive education or professional counseling to reflect the types of crisis problems by gender and school level.

Finally, a survey and research on qualitative research methods for supporting out-of-school youth is needed.

The number of out-of-school teenagers is on the rise every year due to suspension of study. To this end, the law on out-of-school youth support was enacted and the establishment of an out-of-school youth support center seems to be moving in a good direction. However, the current number of out-of-school adolescents does not trust the validity of the results to use quantitative survey methods. Therefore, in order to accurately identify out-of-school teenagers and provide systematic and professional support, it seems necessary to survey and research qualitative research methods for out-of-school youth support.

\section{Reference}

[1] Seoul Economy, Adolescence in statistics, www.seoulsolution.kr/ko/seoul-stats, June 1 (2020)

[2] Yeun, Young-Ran, A Study of Internet Addiction, Depression and Anxiety among Smoking Adolescents, Journal of the Korea Academia-Industrial cooperation Society, (2012), Vol.13, No.11, pp. 5364-5371.

[3] S. J. Lee, A study on improvement measures for suicide prevention policy in Korea, Chonbuk National University, Master's Thesis, (2019)

[4] J. Y. Kim, J. B. Kim, E. J. Jang, Effect of Child Abuse on Binge Drinking and Suicide Ideation among Adolescents, Youth Studies, (2015), Vol.27, No.5, pp.119-145. 
[5] Y. S. Han, The Legislative History and Development of the Probation System, Probation Research, (2009), Vol.9, No.1, pp.21-36.

[6] B. Y. Kim, S. L. Lee, Mobile Phone and Internet Game Addiction, and Stress Responses of High School Students: The Mediating Effect of Sleep Deprivation, Korean Journal of Health Psychology, (2012), Vol.17, No.2, pp.385-398.

[7] C. S. Go, The Effects of Addictive Cell-phone Use of Adolescence on mental health, Youth Culture Forum, (2012), Vol.30, No.1, pp.7-36.

[8] S. L. Hang, A Study on Ecological System Variables Affecting Adolescents' Smartphone Addiction, Chosun University, Master's Thesis, (2013)

[9] J. Y. Gwak, J. Y. Kim, J. H. Lim, A Study on the Effect of Physical Abuse on Relationship Maladjustment between a Teacher and Adolescents: the Mediation Effect of Self-Control, Youth Welfare Research, (2016), Vol.18, No.2, pp.221245.

[10] S. I. Ryu, Factors Affecting Elementary School Students' Smartphone Addiction, Gwangju Women's University, Master's Thesis, (2015)

[11] Olson, The Human Animal: Personal Identity without Psychology, UK: Oxford University Press, (1999)

[12] S. S. Joung, The effect of parental attachment and self-identity on the use of mobile phones in elementary school students, Inje University, Master's Thesis, (2012)

[13] Korea Youth Counseling and Welfare Institute, 2015 Counseling Case Study Book, Korea: Korea Youth Counseling and Welfare Institute, (2016), https://www.kyci.or.kr/fileup/lib_pdf/2016-7.pdf

[14] J. A. Park, The effect of middle school students' self-control ability on smartphone addiction tendency, Jeju National University, Master's Thesis, (2013)

[15] M. S. Jeoung, Trends and Issues of Adolescent's Smart Phone Addiction Research in Korea, The Journal of Korean Society for School \& Community Health Education, (2015), Vol.16, No.3, pp.17-29. 